Ambar Pratiwi, Listiatie Budi Utami. (2018). Isolasi dan Analisis Kandungan Minyak Atsiri pada Kembang Leson. Vol. 4 (1) Pp. 42-47. Doi: https://doi.org/10.23917/bioeksperimen.v4i1.3361

\title{
Isolasi dan Analisis Kandungan Minyak Atsiri pada Kembang Leson
}

\author{
Ambar Pratiwi*, Listiatie Budi Utami \\ Prodi Biologi FMIPA Universitas Ahmad Dahlan Yogyakarta \\ Jl. Prof. Dr. Soepomo, Janturan, Yogyakarta 55165 \\ *Email: ambar@bio.uad.ac.id
}

\begin{abstract}
Kembang Leson used as aromatherapy for the patient's recovery because it can relieve the doldrums. Kembang Leson composition are very diverse, made up of various flowers and rhizomes, and there has been no in-depth studies related to kembang leson essential oils compounds. This study aims to determine the content of kembang leson volatile oil. In this research, essential oils extraction by Stahl distillation method, essential oils were analyzed qualitatively and quantitatively. Qualitative analysis of essential oils include organoleptic observations; while the quantitative analysis of the essential oil is done by gas chromatography-mass spectra (GC-MS). Essential oils are obtained has a liquid, clear, brownish yellow, aromatic odor. The yield of essential oils obtained $0.75 \%(v / w)$. GC-MS analysis obtained 50 constituents of the essential oil, the five components of essential oils which has an area of camphene highest levels are as much as 1.29\%, 4.93\% cymene methyl benzene, camphor $4.75 \%, 7.56 \%$ and cyclohexane methanol curdione $4.83 \%$.
\end{abstract}

Keywords: kembang leson, destilation, essential oil,gas chromatography.

\begin{abstract}
Abstrak
Kembang leson sering dimanfaatkan sebagai aromaterapi pada saat pemulihan bagi pasien karena dipercaya dapat menghilangkan rasa lesu. Komposisi kembang leson sangat beragam, terdiri dari beraneka bunga dan rimpang, serta belum ada kajian mendalam terkait dengan kandungan senyawa terutama minyak atsiri pada kembang leson. Penelitian ini bertujuan untuk mengetahui kandungan minyak atsiri yang terdapat pada kembang leson. Pada penelitian ini dilakukan ekstraksi minyak atsiri dengan metode destilasi Stahl, minyak atsiri yang diperoleh dianalisis kualitatif dan kuantitatif. Analisis kualitatif minyak atsiri meliputi pengamatan organoleptis; sementara analisis kuantitatif minyak atsiri dilakukan dengan kromatografi gas-spektra massa (KG-SM). Minyak atsiri yang diperoleh memiliki bentuk cair, jernih, berwarna kuning kecokelatan, bau aromatis. Rendaman minyak atsiri yang diperoleh sebesar 0,75\% (v/b). Analisis KG-SM diperoleh 50 komponen penyusun minyak atsiri, lima komponen minyak atsiri yang memiliki luas area tertinggi yaitu camphene kadarnya sebanyak 1,29\%, benzene metil cymene 4,93\%, camphor 4,75\%, cyclohexane methanol $7,56 \%$ dan curdione 4,83\%.
\end{abstract}

Kata Kunci: Kembang leson, destilasi, minyak atsiri, kromatografi gas.

\section{Pendahuluan}

Aromaterapi merupakan suatu teknik terapi yang menggunakan minyak atsiri untuk membantu menjaga kesehatan, menyegarkan serta menenangkan (Koensoemardiyah, 2009). Aromaterapi digunakan untuk mempengaruhi emosi seseorang dan membantu meredakan gejala penyakit, karena mempengaruhi sistem limbik di otak yang mempengaruhi emosi, suasana hati, dan memori (Astuti, dkk., 2015). Serta mampu merangsang produksi neurohormon (endorphin dan enchepalin) yang berfungsi untuk menghilangkan rasa sakit, serta serotonin (Perez, 2003). Secara imunologi arometerapi dapat meningkatkan limfosit pada pembuluh darah perifer, meningkatkan $\mathrm{CD}^{8}$ dan $\mathrm{CD}^{16}$ yang berperan dalam imunitas (Kuriyama et al., 2006). Salah satu cara penggunaan aromaterapi adalah dengan menghirup. Ketika menghirup aromaterapi maka minyak atsiri yang terkandung di dalamnya akan mempengaruhi fisik, emosional, dan mental (Muchtaridi dan Moelyono, 2015).

Minyak atsiri merupakan senyawa metabolit sekunderyang termasuk dalam golongan terpen yang disintesis melalui jalur asam mevalonat (Ganjewala, 2009). Minyak atsiri memberikan aroma tertentu dan khas pada tumbuhan (Muchtaridi, 2015). Saat ini minyak atsiri sudah digunakan sebagai parfum, kosmetik, antibiotik, antioksidan, imunostimulan, 
mengurangi stres, dan terapi bagi penyakit ringan (Buchbauer et al., 1991; Sastrohamidjojo, 2004; Buchbauer, 2010). Komponen minyak atsiri apabila terhirup dapat berinteraksi dengan sistem syaraf pusat dan langsung bereaksi dengan sistem olfaktori, yang kemudian akan menstimulasi syaraf pada otak (Buckle, 1999). Senyawa berbau aromatis (minyak atsiri) pada suatu tumbuhan telah terbukti mempengaruhi aktivitas lokomotor pada mencit (Muchtaridi, 2015).

Kajian empirik tentang tumbuhan penghasil senyawa aromatis di Indonesia, terdapat 49 jenis tumbuhan aromatis, 12 jenis di antaranya digunakan sebagai aromaterapi dengan efek menenangkan dan menyegarkan tubuh (Sangat, 1996). Salah satu pemanfaatan tumbuhan sebagai penghasil minyak atsiri yang secara tradisional dimanfaatkan adalah kembang leson. Kembang leson yaitu racikan jamu untuk mandi. Racikan ini terdiri dari berbagai obatobatan herbal yang biasa didapatkan di Jawa Tengah dan DIY (aneka rempah-rempah, seperti kunir, jahe, cengkeh, jinten, pala, aneka dedaunan, aneka bunga, dan lain sebagainya). Semua bahan diseduh dengan air hangat, kemudian dipakai untuk mandi, baik dengan cara biasa maupun berendam. Ketika mandi dengan ramuan ini, efek yang didapat adalah kesegaran dan bau yang wangi.

Secara ilmiah beberapa komponen kembang leson telah dikaji secara mandiri. Menurut Suprianto dan Cahyono (2012), senyawa bioaktif yang terkandung dalam rimpang jahe, seperti senyawa phenolic (shogaol dan gingerol) dan minyak atsiri, seperti zingiberen. Hasil penelitian Prianto $\mathrm{dkk}$ (2013), menunjukkan bahwa minyak cengkeh mengandung 6 komponen yaitu, eugenol 81,2\%, trans-karyofilen $3,92 \%$, alfa-humulen $0,45 \%$, eugenil asetat 12,43\%, karyofilen oksida 0,25\%, dan trimetoksiasetofenon $0,53 \%$. Benzene ethanol atau phenyl ethyl alcohol merupakan senyawa yang mempunyai bau khas (fragrant, aroma) yang disebut kelompok senyawa organik aromatik. Benzene ethanol merupakan jenis eter dengan berat molekul rendah, yang biasanya digunakan sebagai pengharum dan ditemukan dalam minyak esensial. Konsentrasi benzene ethanol atau phenyl ethyl alcohol pada minyak concrete atsiri mawar sebesar 31,58\% (Amiarsi dkk, 2006; Sukardi dkk, 2014).

Berdasarkan kajian-kajian tersebut perlu dikembangkan penelitian yang mengkaji tentang kandungan minyak atsiri pada kembang leson secara utuh sehingga bisa dimanfaatkan sebagai tambahan informasi dalam kajian minyak atsiri.

\section{Metode Penelitian}

\section{Alat dan Bahan}

Komponen kembang leson diperoleh dari Pasar Gamping Sleman, Yogyakarta. Alat yang digunakan adalah seperangkat alat destilasi, erlenmeyer, instrumen GC-MS.

\section{Metode dan Desain Penelitian}

\section{a. Isolasi Minyak Atsiri dengan Distilasi Uap}

Komponen kembang leson yang telah dipotong-potong ditimbang sebanyak $2 \mathrm{~kg}$, kemudian didistilasi selama 6 jam dengan suhu berkisar $100-105^{\circ} \mathrm{C}$. Alat yang digunakan adalah distilator stahl.

\section{b. Penentuan Karakter Organoleptis}

Minyak atsiri yang diperoleh diamati secara orgaoleptis dengan mengamati bentuk, warna, dan aroma.

\section{c. Penentuan Komposisi Senyawa Minyak Atsiri}

Minyak atsiri yang didapatkan diinjeksikan ke injektor KG-SM di Laoratorium Penelitian Terpadu Fakultas Farmasi UAD. Proses KG dilakukan dengan laju alir $1,15 \mathrm{ml} / \mathrm{menit}$, injeksi split, gas pembawa helium tekanan $75 \mathrm{kPa}$, suhu injector $150^{\circ} \mathrm{C}$, suhu interface $225^{\circ} \mathrm{C}$, program suhu $75^{\circ} \mathrm{C}$ ditahan 5 menit hingga $200^{\circ} \mathrm{C}$ ditahan 5 menit (laju kenaikan $20^{\circ} \mathrm{C} / \mathrm{min}$ ).

\section{Hasil dan Pembahasan}

Bagian-bagian tanaman yang digunakan untuk meracik kembang leson memiliki karakteristik tertentu. Bahan baku akan menentukan kualitas minyak atsiri. Kondisi bahan yang optimal mempengaruhi mutu minyak atsiri, misalnya cara pemetikan yang sesuai dan penetuan tingkat ketuaan bahan.

Untuk bagian daun (daun salam, daun pandan, daun sereh, dan jeruk purut) dipilih daun 
yang telah dewasa (membentang sempurna). Pada daun yang telah dewasa dijumpai kandungan minyak atsiri yang lebih banyak ditandai dengan semakin kuatnya aroma minyak atsiri pada daun dewasa tersebut. Sementara daun kelapa digunakan daun yang masih muda, berwarna kuning atau yang umum disebut janur. Bunga yang digunakan, baik bunga mawar dan bunga kenanga dipilih yang telah mekar karena kandungan minyak atsirinya lebih banyak, ditandai dengan semerbak wangi bunga yang telah mekar. Sementara bunga kantil dipilih yang masih kuncup, karena mahkota bunga kantil mudah rontok ketika bunga mekar.

Rimpang yang digunakan juga rimpang yang telah dewasa yang memiliki ukuran maksimal, warna rimpang lebih jelas, senyawa aromatik telah terakumulasi maksimal. Secara ilmiah beberapa komponen kembang leson telah dikaji secara mandiri. Menurut Suprianto dan Cahyono (2012), senyawa bioaktif yang terkandung dalam rimpang jahe, seperti senyawa phenolic (shogaol dan gingerol) dan minyak atsiri, seperti zingiberen. Hasil penelitian Prianto dkk (2013), menunjukkan bahwa minyak cengkeh mengandung 6 komponen yaitu, eugenol $81,2 \%$, trans-karyofilen 3,92\%, alfa-humulen $0,45 \%$, eugenil asetat $12,43 \%$, karyofilen oksida $0,25 \%$, dan trimetoksiasetofenon $0,53 \%$.

Komponen terbanyak yang menyusun kembang leson adalah rimpang-rimpangan (temulawak, temu girin, temu ireng, dan dlingo) dan bunga mawar (Tabel 1.), sehingga menimbulkan aroma yang khas.

Tabel 1 Komponen kembang leson

\begin{tabular}{|c|c|c|}
\hline No. & Nama Bahan & Persentase bahan \\
\hline 1 & Daun sereh & $6,97 \%$ \\
\hline 2 & Daun pandan & $6,10 \%$ \\
\hline 3 & Daun kelapa & $2,09 \%$ \\
\hline 4 & Daun jeruk purut & $2,61 \%$ \\
\hline 5 & Daun salam & $2,61 \%$ \\
\hline 6 & Batang secang & $1,92 \%$ \\
\hline 7 & Rasuk angin & $1,06 \%$ \\
\hline 8 & Biji adas & $0,70 \%$ \\
\hline 9 & Pulosari & $1,26 \%$ \\
\hline 10 & Bunga mawar & $10,46 \%$ \\
\hline 11 & Bunga kenanga & $0,86 \%$ \\
\hline 12 & Bunga kantil & $1,51 \%$ \\
\hline 13 & Bunga melati & $0,16 \%$ \\
\hline 14 & Rimpang temulawak & $22,66 \%$ \\
\hline 15 & Rimpang temugiring & $23,53 \%$ \\
\hline 16 & Rimpang temu ireng & $17,43 \%$ \\
\hline 17 & Rimpang dlingo & $13,07 \%$ \\
\hline 18 & Rimpang bangle & $1,74 \%$ \\
\hline
\end{tabular}

Proses ekstraksi untuk memperoleh minyak atsiri pada kembang leson dilakukan dengan destilasi air Stahl. Kelebihan dari destilasi air adalah prinsip kerja sederhana karena bahan uji direndam dengan air dan didihkan sampai titik didihnya. Hasil destilasi minyak atsiri kembang leson diperoleh sebanyak $15 \mathrm{ml}$ dari $2 \mathrm{~kg}$ kembang leson basah yang didestilasi selama 5 jam. Sehingga diperoleh kadar minyak atsiri dari kembang leson sebesar 0.75\% (v/b). Minyak atsiri yang diperoleh diamati secara organoleptis meliputi bentuk sediaan, warna, dan aroma. Minyak atsiri kembang leson berupa cair, dengan warna kuning, jernih serta aromatik. 
Profil kromatografi gas minyak atsiri kembang leson menunjukkan adanya 50 komponen penyusun. Di antara 50 komponen tersebut ada lima kompenen minyak atsiri yang memiliki luas area tertinggi yaitu camphene kadarnya sebanyak $1,29 \%$, benzene metil cymene $4,93 \%$, camphor $4,75 \%$, cyclohexane methanol $7,56 \%$, dan curdione 4,83\%. Di antara lima minyak atsiri, tiga kompnen merupakan minyak atsiri yang sering dijumpai pada rimpang yaitu camphene, benzene metil cymene, dan camphor (Arniputri et al., 2007).

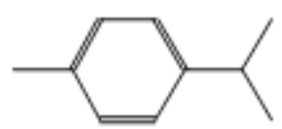

Benzene

metil cymene

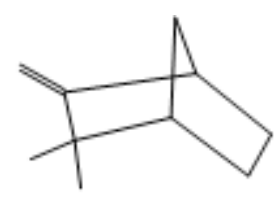

Champene
Struktur kimia masing-masing komponen dengan luas area tertinggi dapat digunakan untuk menentukan golongan minyak atsiri. Lima komponen minyak atsiri yang memiliki luas area tertinggi termasuk golongan monoterpen dan seskuiterpen (Bakkali et al., 2008; Naquvi et al., 2014). Struktur seskuiterpen terdiri dari 2 isopren sehingga memiliki 15 atom $\mathrm{C}$, golongan seskuiterpen tersebar luas pada tumbuhan dan memiliki peran sebagai building block untuk sintesis metabolit yang lain seperti fitohormon, sterol, karoten, struktur fitol pada klorofil (Zwenger and Basu, 2008).
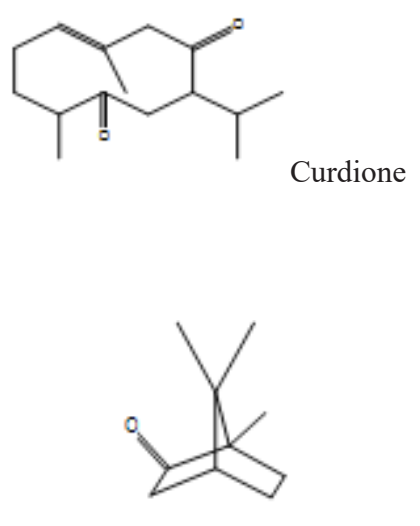

Camphor

Gambar 1. Struktur kimia terpen pada minyak atsiri kembang leson

Biosintesis terpen seperti pada Gambar 1 dapat melalui jalur mevalonat (MVA-mevalonic acid) yang berlangsung di sitosol atau pun jalur metil eritritol fosfat (MEP) yang berlangsung di plastid (Ganjewala, 2009). Pada tumbuhan golongan terpen sangat mendukung pada fungsi pertahana baik terhadap herbivora atau pun stres lingkungan. Selain itu terpen juga mendukung dalam proses polinasi dan pemencaran biji (Bakkali et al., 2008; Zwenger and Basu, 2008).

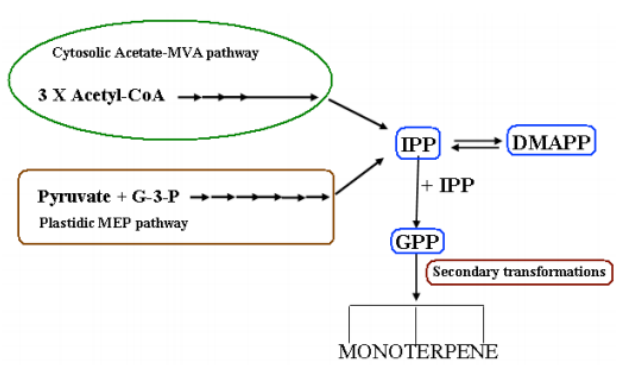

Gambar 2. Biosinetesis terpen pada tumbuhan (Ganjewala, 2009), IPP (isopentenil pirofosfat), DMAPP (dimetilalil pirofosfat), GPP (geranil pirofosfat).

Minyak atsiri memberikan aroma tertentu dan khas pada tumbuhan (Muchtaridi, 2015). Komponen minyak atsiri apabila terhirup dapat berinteraksi dengan sistem syaraf pusat dan langsung bereaksi dengan sistem olfaktori, yang kemudian akan menstimulasi syaraf pada otak (Buckle, 1999). 
Senyawa berbau aromatis (minyak atsiri) pada suatu tumbuhan telah terbukti mempengaruhi aktivitas lokomotor pada mencit (Muchtaridi, 2015).

Adanya variasi pada kandungan minyak atsiri bahan sangat dipengaruhi oleh variasi genetik, letak geografis, waktu pemanenan, tahap pertumbuhan, dan faktor lingkungan (Naquvi et al., 2014). Bakkali et al. (2008) menyatakan bahwa minyak atsiri paling banyak dijumpai pada tanaman aromatis yang tumbuh di Negara tropis dan mediterania.

\section{Simpulan dan Saran}

Kesimpulan dari penelitian ini diperoleh beragam jenis minyak atsiri dari komponen kembang leson, jenis minyak atsiri yang paling banyak ditemukan adalah camphene, benzene metil cymene, camphor, cyclohexane methanol dan curdione. Perlu dilakukan kajian lebih jauh mengenai efek farmakologis kembang leson.

\section{Daftar Pustaka}

Amiarsi, D. Yulianingsih, Sabari S.D. 2006. Pengaruh Jenis dan Perbandingan Pelarut terhadap Hasil Ekstraksi Minyak Atsiri Mawar. Journal of Holticulture. 16(4):356-359.

Arniputri, R.B., A.T. Sakya., M. Rahayu. 2007. Identifikasi Komponen Utama Minyak Atsiri Temu Kunci (Kaempferia pandurata) pada Ketinggian Tempat yang Berbeda. Biodiversitas. 8(2): 135-137.

Astuti, W. Rahayu, H.S.E. Wijayanti, K. 2015. Pengaruh aromaterapi Bitter Orange terhadap Nyeri dan Kecemasan Fase Aktif Kala 1. The $2^{\text {nd }}$ University Research Coloqium. ISSN 2407-9189. 371-382.

Bakkali, F. S. Averbeck, D. Averbeck, M. Idaomar. 2008. Biological Effects of Essential Oils-A Review. Food and Chemical Toxikology. 46: 446-475.

Buchbauer, G., Jager, W., Dietrich, H., Plank, Ch., Karamat, E. 1991. Aromatherapy: Evidence for Sedative Effects of Essensial Oil of Lavender After Inhalation. Journal of Biosciences; 46c: 1067-1071.

Buchbauer, G. 2010. Handbook of Essensial Oils: Science, Technology, and Applications. New York: CRC Press, Taylor and Francis Group.

Buckle, J. 1999. Use of Aromatherapy as Complementary Treatment for Chronic Pain. J. Alternative Therapies. 5: 42-51.

Ganjewala, D. 2009. Cymbopogon Essensial Oils: Chemical Compositions and Bioactivities. International Journal of Essential Oil Therapeutics. 3: 56-65.

Koensoemardiyah. 2009. A-Z Aromaterapi untuk Kesehatan, Kebugaran, dan Kecantikan. Yogyakarta: ANDI.

Kuriya, S., W. Takaaki, N. Ichiro, S. Masakazu, K. Noriko, Y. Daiki, M. Toshiaki T. Kotaro, O. K. Fukui, and J. Imanishi. 2006. Immunological and Psychological Benefits of Aromatherapy Massage. Evidence-Based Complementary and Alternative Medicine 2 (2): 179-184.

Muchtaridi dan Moelyono M.W. 2015. Aroma Terapi; Tinjauan Aspek Kimia Medisinal. Yogyakarta: Graha Ilmu.

Muchtaridi. 2015. Penelitian Pengembangan Minyak Atsiri sebagai Aromaterapi dan Potensinya sebagai Produk Sediaan Farmasi. J. Tek. Ind. Pert. 17(3), 80-88.

Perez, C. 2003. Clinical Aromatherapy Part I: An Introduction Into Nursing Practice. Clinical Journal of Oncology Nursing. 7:5.

Naquvi, K.J., S.H. Anshari, M. Ali, K. Najmi. 2014. Volatile Composition of Rosa damascene (Rosaceae). Journal of Pharmacognosy and Phytochemsitry. 2(5): 177-181. 
Prianto H., R. Retnowati, U. P. Juswono. 2013. Isolasi dan Karakterisasi dari Minyak Bunga Cengkeh (Syzigium aromaticum) Kering Hasil Distilasi Uap. Kimia Student Journal, Universitas Brawijaya, 1(2): 269-275.

Sastrohamidjojo, H. 2004. Kimia Minyak Atsiri. Yogyakarta: Universitas Gadjah Mada.

Sukardi, Rizka N., M. Hindun Pulungan, Arie Febrianto. 2014. Ekstraksi Minyak Atsiri Bunga Mawar dengan Metode Pelarut Menguap Menggunakan Perlakuan PEF. Diakses dari http:// skripsitip.staff.ub.ac.id/files/2014/09/Rizka-Noviaty.pdf. 10 Februari 2016.

Supriyanto dan B. Cahyono. 2012. Perbandingan Kandungan Minyak Atsiri antara Jahe Segar dan Jahe Kering. Chem. Prog. 5(2):81-85.

Zwenger S and C. Basu. 2008. Plant Terpenoids: Applications and Future Potentials. Biotechnology and Molecular Biology Reviews. 3(1): 001-007. 